\title{
Application of Skin Electrodes for Intraoperative Neuromonitoring of Recurrent Laryngeal Nerve
}

\author{
Hyoung Shin Lee \\ Department of Otolaryngology-Head and Neck Surgery, Kosin University College of Medicine, Busan, Korea \\ 피부 전극을 활용한 반회후두신경의 수술 중 신경모니터링 \\ 이형신 \\ 고신대학교 의과대학 이비인후과학교실
}

\author{
Received September 3, 2020 \\ Revised September 13,2020 \\ Accepted September 14, 2020 \\ Address for correspondence \\ Hyoung Shin Lee, MD \\ Department of Otolaryngology- \\ Head and Neck Surgery, \\ Kosin University \\ College of Medicine, \\ 262 Gamcheon-ro, Seo-gu, \\ Busan 49267, Korea \\ Tel $+82-51-990-6470$ \\ Fax $+82-51-990-3257$ \\ E-mail sego78@hanmail.net
}

Efficiency of intraoperative neuromonitoring (IONM) for recurrent laryngeal nerve (RLN) during thyroid or parathyroid surgery has been well established. Electromyogram (EMG) tube has been utilized as a standard method of IONM for RLN. However, limitations of EMG tube including false positive signals due to malposition of the tube and relatively high cost have been issued. Recently, there have been several alternative methods using variable types of skin electrodes to overcome the limitations of conventional EMG tube. These recent methods using skin electrodes will be reviewed in this article.

Korean J Otorhinolaryngol-Head Neck Surg 2021;64(1):1-6

Key Words Electrodes · Electromyogram · Neuromuscular monitoring · Recurrent laryngeal nerve.

\section{서 론}

갑상선 또는 부갑상선 수술 중 반회후두신경을 잘 보존하 는 것은 모든 두경부외과 의사에게 가장 중요하고도 기본적 인 과제 중 하나이다. 근전도(electromyogram, EMG) 튜브를 이용한 수술 중 신경모니터링(intraoperative neuromonitoring, IONM)은 수술 중 반회후두신경(recurrent laryngeal nerve, RLN)의 위치를 예측하고 확인할 뿐만 아니라 수술 후 신경의 기능을 예측할 수 있는 방법으로 활용되고 있다.1,2) 그러나, 수술 중에 $\mathrm{EMG}$ 튜브가 회전하거나 상하로 이동하여 $\mathrm{EMG}$ 튜브의 표면 전극과 성대의 접촉이 되지 않으면 IONM 을 시행할 수 없게 된다. 이를 예방하기 위해 기도삽관 후 굴 곡형 후두내시경으로 전극의 위치를 확인하는 것이 권장되

This is an Open Access article distributed under the terms of the Creative Commons Attribution Non-Commercial License (https://creativecommons.org/licenses/by-nc/4.0) which permits unrestricted non-commercial use, distribution, and reproduction in any medium, provided the original work is properly cited.
고 있으나, 현실적으로 쉽지 않은 일이다.,3) 또한 수술 중에 이런 일이 발생하면 수술을 중단하고 마취과의 협조하에 튜 브의 위치를 바로잡는 일도 여러모로 불편할 수 있다. 또한, EMG 튜브의 위치 변화로 위양성 신호소실(false positive signal loss)이 발생하여 신경의 기능에 문제가 없는데도 신경 손상을 염려해야 할 상황이 발생할 수 있다. 약 10 15\%에서 위양성 신호소실이 발생할 수 있는데, ${ }^{4,5)}$ 이는 수술자에게 혼 란을 주어 잘못된 결정을 내리게 할 수 있으므로 IONM을 방해하는 주요인으로 꼽히고 있다. 또한, 국내에서는 $\mathrm{EMG}$ 튜브가 재수술, 경부 림프절 전이, 종양의 국소 침범이 의심 되는 경우(T4) 등 RLN의 손상 위험이 높을 것으로 예상되는 경우에만 사용이 허가된 상태이므로 IONM의 장점에도 불 구하고 상당수의 갑상선 또는 부갑상선 수술에는 활용하지 못하는 문제점이 있다.

$\mathrm{EMG}$ 튜브를 이용한 IONM의 한계를 극복하기 위해 다양 한 피부 전극을 이용하여 성대 근육에 발생한 전기적인 신호 
를 모니터링할 수 있는 방법들이 소개되었다. ${ }^{4-7)}$ 이와 같은 방법들이 보험 적용하에 임상에 적용되기 위해서는 추가적인 연구와 보건 당국의 허가 등 여러 절차가 필요하다. 그럼에도 불구하고, EMG 튜브를 대체할 수 있는 대안 기술로서 피부 전극을 이용한 IONM을 이해하고 익혀 두면 EMG 튜브를 사용할 수 없는 경우에 활용할 수 있고 향후 해당 기술을 발 전시키는 데 도움이 될 것으로 기대한다. 이번 리뷰에서는 $\mathrm{EMG}$ 튜브를 대체할 수 있는 피부 전극 중 바늘 전극(needle electrode)과 부착형 표면 전극(adhesive surface electrode) 을 이용한 다양한 IONM 방법에 대해 소개하고자 한다.

\section{본 론}

$\mathrm{IONM}$ 을 위한 피부전극은 크게 바늘 전극과 표면 전극으 로 나누어 볼 수 있다. 현재 가장 많이 활용되고 있는 $\mathrm{EMG}$ 튜브는 기관삽관튜브에 부착된 표면 전극이 성대와 접촉한 상태에서 전기 신호를 전달 받는 원리로 사용되고 있다. ${ }^{2}$ 성 대근육(vocalis muscle, thyroartyenoid muscle) 외에도 후 두의 유일한 외전근인 후윤상피열근(posterior cricoarytenoid muscle)를 모니터링할 수 있는 후윤상 전극 ${ }^{8)}$ 등도 보고 된 바 있으나 널리 활용되고 있지는 않으므로 이번 리뷰에서 는 제외한다.

\section{바늘 전극(Needle electrode)}

\section{갑상연골 삽입(Trans-cartilaginous insertion)}

2017년 Chiang 등)이 바늘 전극을 이용한 IONM을 소개 하였다. 두 개의 single needle electrode(Medtronic Xomed, Jacksonville, FL, USA)를 갑상연골의 외측면에 비스듬히 (oblique) 삽입하여 IONM을 시행했다. 바늘 삽입이 연골막 하에 국한되도록 하여 후두 내의 혈종이나 점막 손상 등을 피하는 것이 중요하다. 바늘 전극을 통해 얻은 신호의 amplitude가 EMG 튜브에서 얻은 것에 비해 유의하게 높게 나 타났으며, $\mathrm{EMG}$ 튜브에서 발생한 3건의 위양성 신호소실이 바늘 전극에서는 발생하지 않아 더 높은 정확도를 보였다. 바늘 전극을 삽입하는데 소요된 시간은 약 2 분으로 수술 시 간에 큰 영향을 주지 않았고, 잘 고정하면 수술 중에 수술자 가 전극의 상태를 안정적으로 관찰하면서 IONM을 시행할 수 있다. 그러나 갑상연골을 상방까지 충분히 노출해야 전극 을 삽입할 수 있으므로 피부 절개선이 작거나 피부 피판이 충분히 박리되지 않으면 전극 삽입에 어려움이 있을 수 있다. 바늘 전극은 하나의 전극에 두 개의 바늘이 있는 paired needle electrode(Medtronic Xomed)를 사용해도 가능하다
(Fig. 1A).9) 국내에서는 Jung 등이 이 두 개의 $22 \mathrm{~mm}$ twisted pair needle electrode(Medtronic Xomed)를 양측 갑상연골 에 삽입하여 IONM이 가능함을 보고한 바 있다. 바늘 전극 을 통해 얻은 신호는 EMG 튜브에서 얻은 것보다 높은 amplitude를 보였으며 EMG 튜브의 양성예측도가 $40 \%$ 로 낮은 반면, 바늘 전극의 경우 $100 \%$ 의 높은 양성예측도를 얻을 수 있었다. 즉, 바늘 전극을 이용하면 위양성 신호소실을 완전하 게 피할 수 있다는 것이다.

최근에는 하나의 dual paired needle electrode(DSN 2299, Medtronic Xomed)를 일측 갑상연골에만 삽입하여 IONM 을 시행할 수 있다는 보고가 있었다(Figs. $1 \mathrm{~B}$ and $2 \mathrm{~A}$ ). ${ }^{11}$ 특히 국내의 경우 갑상선 일측엽 절제술을 시행 받는 환자들은 대 부분 $\mathrm{EMG}$ 튜브가 보험 적용될 수 없어 이와 같은 바늘 전 극의 효용성이 높다고 판단된다. Lee 등1에 의하면 갑상연 골을 상방까지 충분히 노출하지 않더라도 갑상연골의 하방 일부만 노출한 후에 바늘의 방향을 하방에서 상방으로 비스 듬히 삽입해도 IONM을 시행하는 데 문제가 없다. 단, Chiang 등 ${ }^{4}$ 이 언급한대로 고령의 환자는 연골의 석회화 때문에 삽입이 어려울 수 있고 갑상선이 비대한 경우나 비만 환자의 경우 갑상연골이 충분히 노출되기 어려운 경우가 있다. Lee 등1의 연구에서 사용한 바늘의 길이는 $12 \mathrm{~mm}$ 인데, 갑상연 골의 석회화 또는 노출 정도에 따라 바늘이 $5 \mathrm{~mm}$ 보다 짧게 삽입된 경우에는 바늘이 $5 \mathrm{~mm}$ 이상 깊이 삽입된 경우에 비 해 낮은 신호 amplitude를 보였다. 그러나, 바늘 삽입이 $5 \mathrm{~mm}$ 이하였던 환자군에서도 평균 $591 \sim 860 \mu \mathrm{V}$ 의 진폭을 얻을 수 있어 IONM을 시행하는 데는 문제가 없었다.

\section{윤상갑상막(Cricothyroid membrane) 삽입}

윤상갑상막을 통해 바늘 전극을 삽입하는 시도들이 있었 는데 초기 연구에서는 중앙에서 후두 내부로 paired needle 을 삽입하여 성대 내부로 바늘이 삽입되는 위험이 있었다. ${ }^{12,13}$ 이를 보완하기 위해 $\mathrm{Li}$ 등 ${ }^{14}$ 은 두개의 paired needle 전극을 갑상연골의 하연을 통해 성대근육을 향해 상방 외측으로 삽 입하는 방법으로 성대 손상 위험을 최소화하여 IONM을 시 행할 수 있다고 보고했다(Fig. 1C). 연구에 포함된 92명 중 2 명의 환자에서 5 분간의 압박이 필요했던 출혈이 있었으나 혈종이나 감염 등의 합병증은 없었다고 한다.

\section{피부 삽입(Transcutaneous insertion)}

부갑상선 절제술 시에 두 개의 paired needle 전극을 피부 를 통해 직접갑상연골 양측에 삽입하여 IONM을 시행한 연 구가 최근 보고되었다(Fig. 1D). ${ }^{7}$ 총 20명의 환자 중 5명은 갑 상연골의 석회화로 바늘 삽입에 어려움이 있었고 초기 진폭 


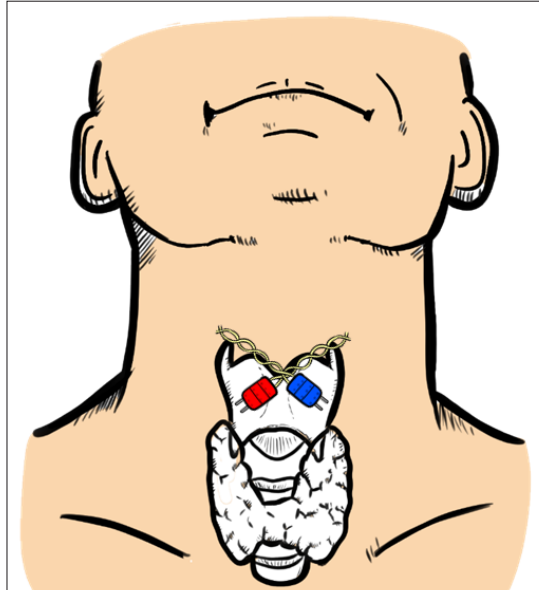

A

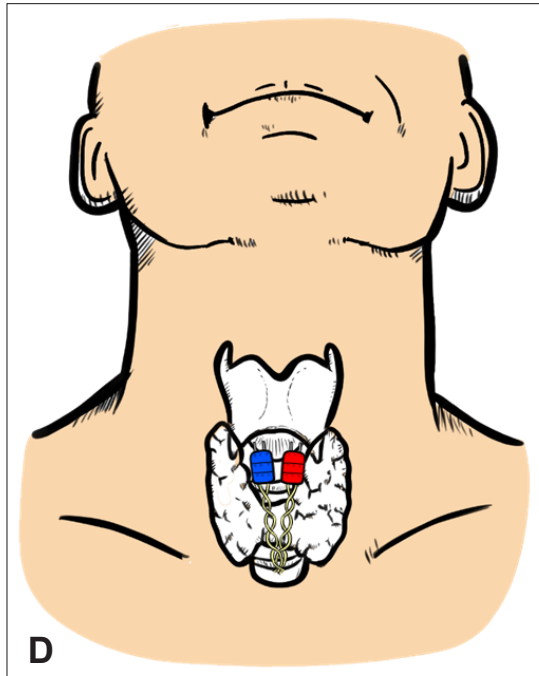

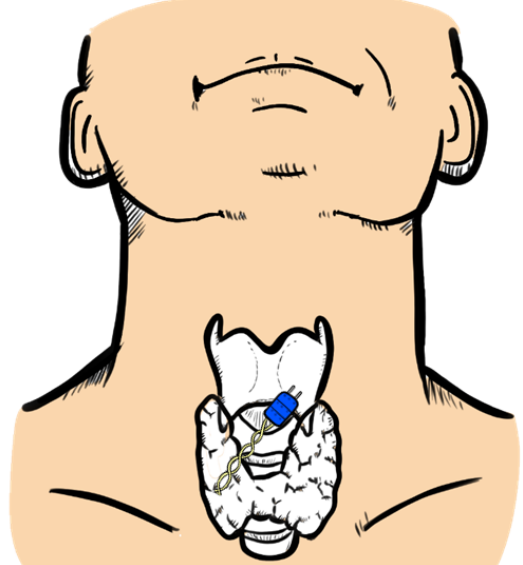

B

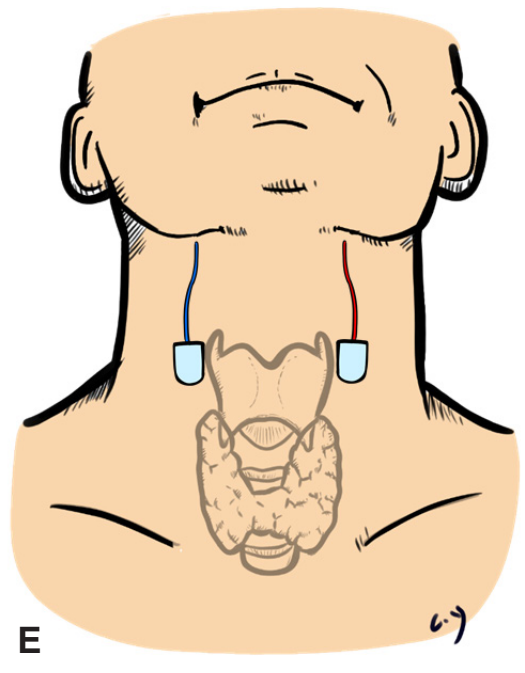

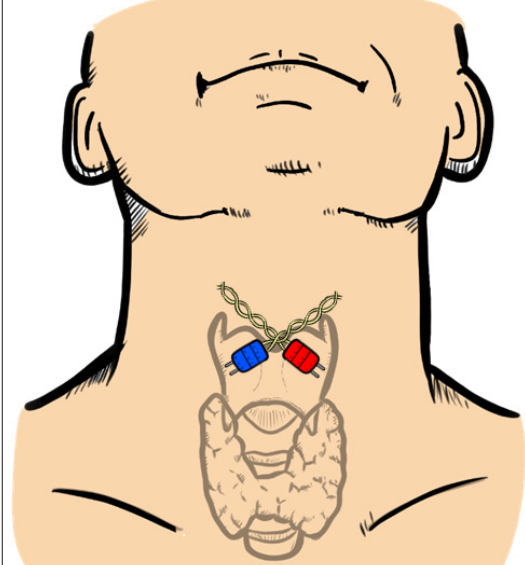

c.)

Fig. 1. Illustration of various types of skin electrodes applied for intraoperative neuromonitoring of recurrent laryngeal nerve. Two paired needle electrode inserted to both thyroid cartilage (A). One paired needle electrode inserted to unilateral thyroid cartilage (B). Two paired needle electrodes inserted to skin and to both thyroid cartilage (C). Two paired needle electrodes inserted to cricothyroid space (D). Two adhesive skin electrodes attached to skin (E). Two adhesive skin electrodes attached to both thyroid cartilage (F).

의 크기가 $500 \mu \mathrm{V}$ 이하로 나오는 한계가 있었지만 바늘 삽입 에 따른 합병증 없이 평균 $1000 \mu \mathrm{V}$ 이상의 높은 신호 진폭을 획득할 수 있었다. 이 방법은 갑상연골을 직접 노출할 필요 가 없다는 장점이 있지만 바늘 전극의 길이가 $12 \mathrm{~mm}$ 이므로 비만 환자에서는 사용이 제한될 수 있다. 또한 전극 삽입 과 정에서 피부와 연골 사이에 주행하는 혈관이 손상될 수 있 어 혈종이 발생할 가능성을 고려해야 한다.

부착형 표면 전극(Adhesive surface electrode)

피부 부착(Skin attachment, Transcutaneous)

2018년 Wu 등히이 부착형 표면 전극을 피부에 부착하여 갑상선 수술 중 IONM이 가능함을 동물실험을 통해 보고하
였다. 피부에 부착된 표면 전극을 통해 얻은 amplitude는 미 주신경 $(202 \mu \mathrm{V}: 776 \mu \mathrm{V})$ 과 반회후두신경 $(264 \mu \mathrm{V}$ :907 $\mu \mathrm{V})$ 모두 EMG 튜브에서 얻은 신호보다 유의하게 낮았다. 그러나 $\mathrm{EMG}$ 튜브의 위치를 의도적으로 이동시켜 성대와의 접촉이 떨어지도록 하여 amplitude가 떨어지는 실험 조건에서도, 피 부 부착형 표면 전극을 통해 얻은 $\mathrm{EMG}$ 신호에는 변화가 없 었다. 이는 부착형 표면 전극을 이용한 IONM도 바늘 전극을 이용한 경우와 마찬가지로 $\mathrm{EMG}$ 튜브 변위(malposition)에 따른 위양성 신호 감소 또는 소실을 피할 수 있는 방법임을 제시한다.

Lee 등)은 부착형 표면 전극(DSE 3125, Medtronic Xomed) 을 갑상 연골의 양측 상방 피부에 부착하여 25명(39 nerve at risk)의 갑상선 수술 환자에서 IONM이 가능함을 보고하였 

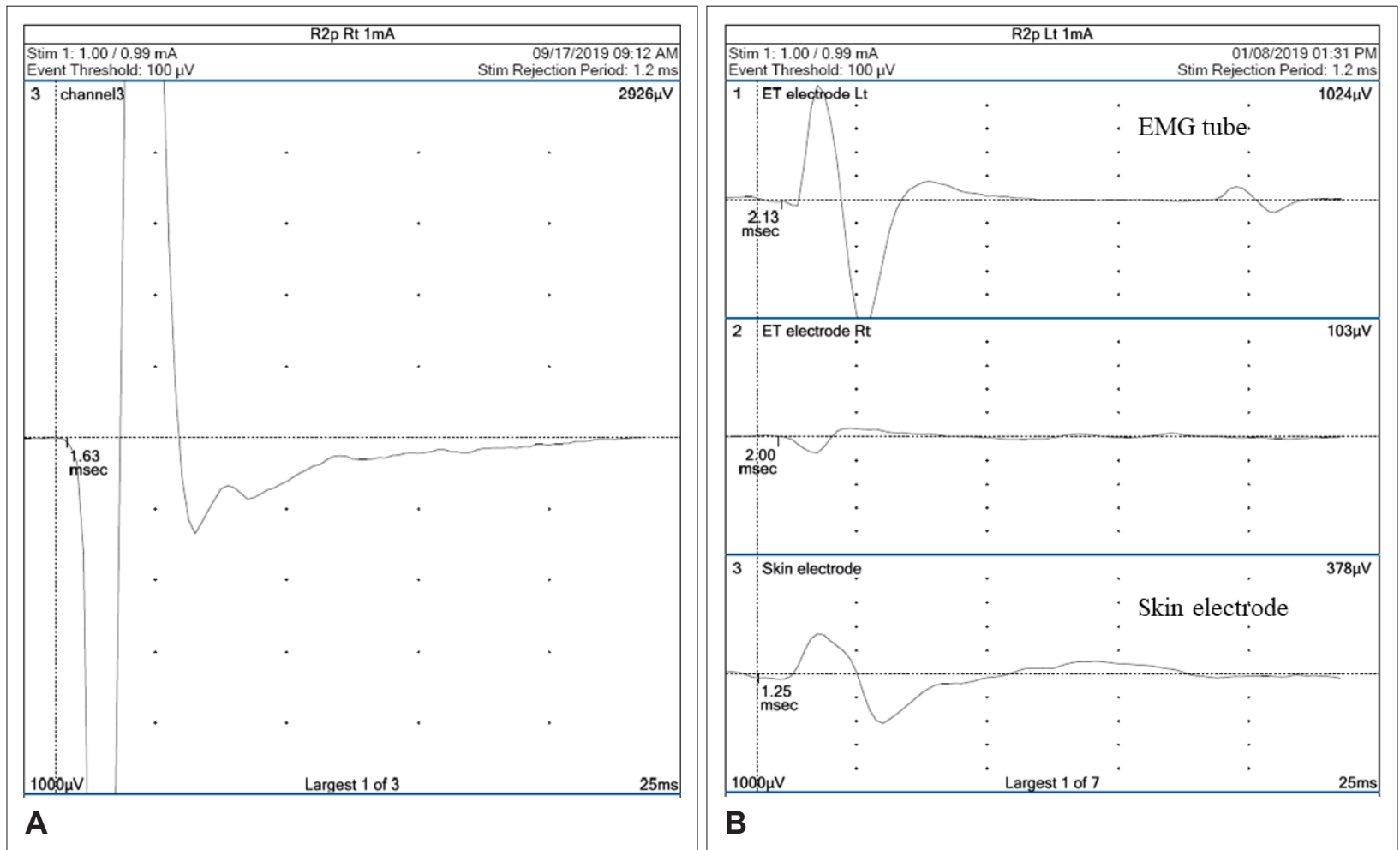

Fig. 2. EMG acquired from skin electrodes. Signal from intra-cartilaginous needle electrode shows amplitude of $2026 \mu V(A)$. Signal from skin electrode attached to anterior neck skin shows lower amplitude (378 $\mu \mathrm{V})$ in comparison to that from EMG tube (1024 $\mu \mathrm{V})(\mathrm{B})$. EMG: electromyogram.

다(Figs. $1 \mathrm{E}$ and $2 \mathrm{~B}) . \mathrm{Wu}$ 등 ${ }^{15)}$ 이 보고한 동물 실험 결과와 같 이 표면 전극에 의한 $\mathrm{EMG}$ 신호는 $\mathrm{EMG}$ 튜브에 의한 신호에 비해 amplitude가 약 1/4로 낮게 나타났다. 그러나, EMG 튜 브에서 발생한 4건(10.3\%)의 위양성 신호소실이 부착형 표면 전극에 의한 $\mathrm{EMG}$ 신호에서는 나타나지 않아 피부에 부착된 표면 전극이 $\mathrm{EMG}$ 튜브의 변위에 따른 한계점을 극복할 수 있음을 보여 주었다. 또한, 해당 연구에 사용된 표면 전극은 $\mathrm{EMG}$ 튜브에 비해 월등한 가격 경쟁력이 있으므로 $\mathrm{EMG}$ 튜 브를 사용할 수 없는 경우나 사전에 준비가 되지 않은 경우 에 대안이 될 수 있음을 기술하고 있다.

피부 부착형 표면 전극을 이용한 IONM은 현재까지 보고 된 방법 중에 가장 안전한 방법으로 평가된다. 그러나 $\mathrm{EMG}$ 튜브에 비해 낮은 amplitude는 분명한 한계로 지적되고 있다. 향후 전극 관련 기술 개발을 통해 amplitude를 높이고 갑상 선 또는 부갑상선 수술에 최적화된 디자인의 전극이 개발된 다면 더욱 널리 활용될 수 있을 것으로 기대된다. 전자 피부 (electronic skin) ${ }^{16)}$ 개발도 이를 극복할 수 있는 대안이 될 수 있다. ${ }^{6}$

갑상연골 부착(Thyroid cartilage attachment)

2018년 Wu 등은 갑상연골을 노출시킨 후 피부 부착용 표
면 전극(adhesive pre-gelled electrode, Neotrode II, ConMed Corp., Utica, NY, USA) 한 쌍을 연골 양쪽 측면에 부착하 여 IONM을 시행하는 방법을 보고하였다(Fig. 1F). 이 방법 역시 $\mathrm{EMG}$ 튜브의 변위와 관계 없이 안정적인 $\mathrm{EMG}$ 신호를 얻을 수 있었고 amplitude도 미주 신경에서 $607 \mu \mathrm{V}$, 반회후 두신경에서 $695 \mu \mathrm{V}$ 를 얻어 $\mathrm{EMG}$ 튜브에 비해서는 다소 낮으 나 피부에 전극을 부착한 경우에 비해 높은 amplitude를 획 득하였다. 그러나, 저자들은 갑상연골을 충분히 노출하기 위 해서 피부 절개선이 충분히 길어야 하며, 수술시간이 다소 연 장될 수 있으며, 피부 부착용 전극의 크기가 커서 갑상연골에 부착하기에는 크기가 제한점이라고 기술했다. 그리고, shunt stimulation이 발생하면 주변의 근육에서 발생한 신호가 기 록될 수 있는 점도 유의 사항이다. 또한, 표면 전극이 갑상연 골에서 떨어질 수 있는 위험이 있으므로 향후 갑상연골에 안 정적으로 부착할 수 있는 전극이 개발된다면 $\mathrm{EMG}$ 튜브의 대안으로 고려해 볼 수 있을 것이다.

부착형 표면 전극(Dragonfly bipolar surface electrode, Neurovision Medical Products, Ventura, CA, USA)을 갑 상연골에 부착해서 IONM을 시행한 Van Slycke 등ㄱㅇㅢ 연 구에서는 EMG 튜브의 신호에 비해 높은 amplitude를 얻은 반면 Liddy 등 ${ }^{18}$ 의 연구에서는 EMG 튜브 신호의 $83 \%$ 이하 
Table 1. Summary of studies which applied various skin electrodes for intraoperative neuromonitoring of recurrent laryngeal nerve

\begin{tabular}{|c|c|c|c|}
\hline & $\begin{array}{c}\text { Mean V } 1 \\
\text { amplitude }(\mu \mathrm{V})\end{array}$ & $\begin{array}{c}\text { Mean R1 } \\
\text { amplitude }(\mu \mathrm{V})\end{array}$ & $\begin{array}{l}\text { (+) Advantages } \\
\text { (-) Disadvantages }\end{array}$ \\
\hline \multicolumn{4}{|l|}{ Needle electrode } \\
\hline \multirow[t]{2}{*}{ Transcartilage } & & & (+) High amplitude, good stability, easy insertion \\
\hline & & & (-) Invasiveness, lower signal in calcified cartilage \\
\hline Chiang, et al. ${ }^{4.9}$ & 1652 & 2225 & Two single/paired needle electrode \\
\hline Lee, et al. ${ }^{11)}$ & 1327 & 1942 & One paired needle electrode \\
\hline \multirow[t]{2}{*}{ Cricothyroid space } & & & (+) High amplitude, good stability, easy insertion \\
\hline & & & (-) Invasiveness to vocal cord \\
\hline $\mathrm{Li}$, et al. ${ }^{14)}$ & 1857 & 2347 & Two paired needle electrode \\
\hline \multirow[t]{2}{*}{ Transcutaneous } & & & (+) High amplitude, good stability, no cartilage exposure \\
\hline & & & (-) Invasiveness, lower signal in calcified cartilage, limited for obese neck \\
\hline Li, et al..$^{7}$ & 1124 & 1208 & Two paired needle electrode \\
\hline \multicolumn{4}{|c|}{ Adhesive surface electrode } \\
\hline \multirow[t]{2}{*}{ Transcutaneous } & & & (+) Non-invasive, stable, convenience \\
\hline & & & (-) Low amplitude \\
\hline Lee, et al..$^{5}$ & 186 & 244 & \\
\hline \multirow[t]{2}{*}{ Transcartilage } & & & (+) Non-invasive, similar signal to electromyogram tube \\
\hline & & & (-) Require dissection of cartilage, detachment risk \\
\hline Van Slycke, et al. ${ }^{17)}$ & 785 (left) & 760 (left) & \\
\hline Liddy, et al. ${ }^{18)}$ & 806 & 1117 & \\
\hline
\end{tabular}

로 다소 낮은 amplitude를 보였다. 두 연구 모두 수술자가 전 극의 상태를 감시할 수 있으므로 마취과 의사의 도움 없이 또 한, 튜브의 상태와 관계없이 IONM을 안정적으로 시행할 수 있는 것을 장점으로 꼽았다. 한편, Van Slycke 등ㄱ)은 Prolene 5.0 를 이용하여 전극을 연골막에 고정하는 방법을 소개하기 도 했다.

\section{피부 전극의 한계와 향후 과제}

피부 전극을 이용한 IONM은 많은 장점에도 불구하고 아 직까지 보편적으로 활용되기에는 몇가지 제한점들이 있다 (Table 1). 선행 연구에서 보고된 피부 전극들은 바늘형, 부착 형 모두 경부 수술의 IONM을 위해 제작된 제품이 아니므로 갑상선 또는 부갑상선 수술에 최적화된 크기와 모양의 전극 개발이 필요하며 이를 상품화하기 위한 제조사와의 협력이 필요할 수 있다. 특히 피부 부착형 표면 전극의 경우 amplitude가 낮고 주변 환경에 따라 잡음이 발생하는 문제들이 있 어 향후 이를 극복할 수 있는 전극 개발이 요구된다. 또한, 이 와 같이 피부 전극을 IONM에 사용하는 것은 국내에서 보험 적용이 되지 않으므로 대규모 다기관 연구 결과를 기반으로 유관 학회들이 신의료기술 등록을 진행하는 등의 노력이 필 요할 것으로 보인다. 피부 전극을 이용한 반회후두신경 IONM 이 활성화되면 갑상선, 부갑상선 수술뿐만 아니라 반회후두 신경 손상의 위험이 있는 식도, 대동맥 수술 등에도 활용될 수 있을 것으로 기대된다.

\section{결 론}

피부 전극을 이용한 반회후두신경 IONM은 바늘형 또는 부착형 표면 전극을 이용해서 다양한 방식으로 갑상선 또는 부갑상선 수술 시에 사용될 수 있다. 그러나, 해당 수술에 최 적화된 조건을 갖춘 피부 전극을 개발하기 위해서는 전극을 삽입하거나 부착하는 부위의 해부학적 특성을 고려한 제품 디자인이 요구될 뿐만 아니라 IONM에 적합한 amplitude를 획득할 수 있는 전극 소재 개발 등의 기술적 발전이 필요할 것 으로 보인다. 이를 통해 $\mathrm{EMG}$ 튜브의 제한점을 극복할 수 있 는 대안으로써 피부 전극이 널리 활용될 수 있기를 기대한다.

\section{Acknowledgments}

I would like to express my special appreciation and thanks to professor Young Choi (Department of Orthopedics, Kosin University College of Medicine) for the illustrations.

\section{ORCID}

Hyoung Shin Lee https://orcid.org/0000-0002-6200-1979

\section{REFERENCES}

1) Wong KP, Mak KL, Wong CK, Lang BH. Systematic review and meta-analysis on intra-operative neuro-monitoring in high-risk thyroidectomy. Int J Surg 2017;38:21-30.

2) Randolph GW, Dralle H; International Intraoperative Monitoring Study Group, Abdullah H, Barczynski M, Bellantone R, et al. Electrophysiologic recurrent laryngeal nerve monitoring during thyroid and parathyroid surgery: International standards guideline 
statement. Laryngoscope 2011;121 Suppl 1:S1-16.

3) Chiang FY, Lee KW, Chen HC, Chen HY, Lu IC, Kuo WR, et al. Standardization of intraoperative neuromonitoring of recurrent laryngeal nerve in thyroid operation. World J Surg 2010;34(2):2239.

4) Chiang FY, Lu IC, Chang PY, Dionigi G, Randolph GW, Sun H, et al. Comparison of EMG signals recorded by surface electrodes on endotracheal tube and thyroid cartilage during monitored thyroidectomy. Kaohsiung J Med Sci 2017;33(10):503-9.

5) Lee HS, Oh J, Kim SW, Jeong YW, Wu CW, Chiang FY, et al. Intraoperative neuromonitoring of recurrent laryngeal nerve during thyroidectomy with adhesive skin electrodes. World J Surg 2020; 44(1):148-54

6) Wu CW, Chiang FY, Randolph GW, Dionigi G, Kim HY, Lin YC, et al. Feasibility of intraoperative neuromonitoring during thyroid surgery using transcartilage surface recording electrodes. Thyroid 2018;28(11):1508-16.

7) Li P, Liang QZ, Wang DL, Han B, Yi X, Wei W, et al. The transcutaneous electromyography recording method for intraoperative neuromonitoring of recurrent laryngeal nerve during minimally invasive parathyroidectomy. Sci Rep 2020;10(1):7609.

8) Marcus B, Edwards B, Yoo S, Byrne A, Gupta A, Kandrevas J, et al. Recurrent laryngeal nerve monitoring in thyroid and parathyroid surgery: The University of Michigan experience. Laryngoscope 2003;113(2):356-61.

9) Chiang FY, Wu CW, Chang PY, Wu SH, Chen HY, Lin YC, et al. Trans-thyroid cartilage recording for neural monitoring of the recurrent laryngeal nerve in thyroid surgery. Laryngoscope 2020; 130(4):E280-3.
10) Jung SM, Tae K, Song CM, Lee SH, Jeong JH, Ji YB. Efficacy of transcartilaginous electrodes for intraoperative neural monitoring during thyroid surgery. Clin Exp Otorhinolaryngol 2020;13(4):422-8.

11) Lee HS, Seo SG, Kim DY, Kim SW, Choi Y, Lee KD. Intraoperative neuromonitoring using a single transcartilage needle electrode during thyroidectomy. Laryngoscope. In press 2020.

12) Petro ML, Schweinfurth JM, Petro AB. Transcricothyroid, intraoperative monitoring of the vagus nerve. Arch Otolaryngol Head Neck Surg 2006;132(6):624-8.

13) Alon EE, Hinni ML. Transcricothyroid electromyographic monitoring of the recurrent laryngeal nerve. Laryngoscope 2009; 119(10):1918-21

14) Li P, Liang QZ, Wang DL, Han B, Yi X, Wei W. Modified arytenoid muscle electrode recording method for neuromonitoring during thyroidectomy. Gland Surg 2019;8(5):469-76.

15) Wu CW, Chiang FY, Randolph GW, Dionigi G, Kim HY, Lin YC, et al. Transcutaneous recording during intraoperative neuromonitoring in thyroid surgery. Thyroid 2018;28(11):1500-7.

16) Kim DH, Lu N, Ma R, Kim YS, Kim RH, Wang S, et al. Epidermal electronics. Science 2011;333(6044):838-43.

17) Van Slycke S, Van Den Heede K, Magamadov K, Brusselaers N, Vermeersch $\mathrm{H}$. New placement of recording electrodes on the thyroid cartilage in intra-operative neuromonitoring during thyroid surgery. Langenbecks Arch Surg 2019;404(6):703-9.

18) Liddy W, Lawson BR, Barber SR, Kamani D, Shama M, Soylu S, et al. Anterior laryngeal electrodes for recurrent laryngeal nerve monitoring during thyroid and parathyroid surgery: New expanded options for neural monitoring. Laryngoscope 2018;128(12):2910-5.

\section{정답 및 해설}

1. 답 (1)

해 설 두부외상으로 인한 우측 귀의 malleus가 incus 와 분리되어 전도성 난청이 발생하였다. 이경검사에서 malleus handle의 전위가 관찰되고 측두골 단층촬영에서 malleus가 incus와 분리되어 정상적인 ice cream cone 모양이 소실되어 있다. 관상면에서 malleus의 전위를 관찰할 수 있다. 참고 문헌: 대한이비인후과학회. 이비인후과학:이과. 개정2판. 파주: 군자출판사;2018. p.505-17.

2. 답 (4)

양측성 이경화증으로 우측의 전도성 난청이 더 심하다. 측두골 단층촬영에서 양쪽의 halo sign이 보이며, 수술 내시경 소견에서 등골이 불투명하며 두꺼워진 것이 관찰된다. 고도 난청이더라도 등골수술을 통해 전도성 난청을 해결하고 보 청기 등의 착용을 고려할 수 있기 때문에 수술을 시행하는 것이 도움이 된다. MRI는 골성 병변을 확인하는 데 도움이 되 지 못한다.

참고 문헌: 대한이비인후과학회. 이비인후과학:이과. 개정2판. 파주: 군자출판사;2018. p.491-504. 